\title{
Small Earth Dams in Nigeria: Prospects and Challenges
}

\author{
Bilyaminu Alhassan Amina I. Saddik Nafi’u Tijjani J.U. Abaka Alhassan H. Gumel. \\ Department of Renewable Energy, Energy Commission of Nigeria
}

\begin{abstract}
The study investigates the challenges and prospects of earth dams in Nigeria with emphasis on dams owned by the River Basin Development Authorities of the Federal Ministry of Agriculture and Water resources using Cham dam in Gombe State as case study. The general causes of earth dam failure were considered with emphasis on failures due to engineering factors. The dam water provides raw water for the supply of potable wholesome water to the community all year round and some for irrigated agriculture that not only boost the local economy and reduces poverty but also support a viable livestock management. Cham dam failed in September 1998 after commissioning in December 1992 as a result of poor planning, inadequate study, inconsistent design, un-engineered construction and lack of dam safety monitoring team at site. Based on the findings, suggestions were given on how some earth dam failures in Nigeria can be minimized in terms of adequate feasibility studies, good design, appropriate construction and an improved maintenance culture.
\end{abstract}

Keywords: Small earth dams, un-engineered construction, environmental management, prospects SED, hydraulic failure.

DOI: $10.7176 / \mathrm{JETP} / 9-5-02$

Publication date:June $30^{\text {th }} 2019$

\section{INTRODUCTION}

Dams are manmade water resources developments of various magnitudes that result in harnessing water for man's vital physiological (biological), economic and industrial needs. Their development, at least in the recent times, has been found to involve wide scale ecological transformations. Throughout civilization, man has been known to be so dependent on water that right from the early man, his growth and development from early civilizations have revolved around water bodies like the Nile to the Egyptian as the Euphrates and Tigris to the Mesopotamian civilizations. Even till today there is hardly any human settlement that is not within serviceable boundaries to a water source. It is in this regard that dams as anthropogenic interventions are still being vigorously pursued to supplement natural water bodies in the support and sustainability of human civilizations. This is in terms of harnessing water to supply drinking water for human consumption and development, provide water for irrigation, hydroelectricity, industrial processes and ensure flood water control. It has been estimated that over 40,000 large dams and 800,000 small dams have been built, while 272 million hectares have been put to irrigation worldwide (Keiser et al, 2005). This magnitude of developments has individually and collectively been reported to result in numerous ecological modifications, most of which have negative impacts on the environment and ultimately the state of wellbeing of the human populace. Notable among these is the prevalence of water borne and water related vector borne diseases such as malaria, schistosomiasis, and onchocerciasis among others. Most large dams and sometimes their attendant irrigation schemes also involve displacement of persons causing a disruption in the socio-cultural heritage and orientation of the resident populace. Also the management of these large dams and their irrigation schemes has not been host community friendly such that while they generate little

Economic benefits to the local and further communities they result in enormous failures (adverse impacts)most especially on the host communities, resulting in deprivation, poverty and disease. It is in this regards that recent opinions have favoured small dams and irrigation schemes which can be more efficiently managed to drastically reduce these adverse effects of large dams and irrigation schemes.

In Nigeria, most dams are constructed mainly by the Federal Ministry of Agriculture and Water Resources about $81 \%$ of which consisted of earth dams (Gundiri, 2004). Earth dams were made even popular since the creation of River Basin Development Authorities (R.B.D.A) under the Federal Ministry of water resources and Rural Development by Decree NO. 25 of 1976 (Toro, 1992).

Dams are constructed to intercept run off and create a reservoir. The reservoir can be utilized to regulate runoff for use in any of the following two broad categories:

a) Conservation: This implies storage of surplus water at high flows for utilization at periods of deficient flows. This utilization could be for one or more of several purposes, for example, water supply, agriculture, hydro-power, navigation and even aesthetics.

b) Flood control: This entails regulation of floods by storing some of the flood flow and releasing it gradually later. 


\section{POSITIVE IMPACTS OF SMALL EARTH DAMS \\ 2.1 Flood Water Control}

The dam has significantly reduced flood water flow around the environment. This is because the collection of the hillside runoff in the impoundment greatly dissipates it of its erosive energy there by rendering it less erosive and less degrading to the soil resources in the area. There has been a significant reduction in the devastation to household and structures due to the flooding incidences especially during the rainy seasons. Also the ever increasing fear of flooding and its devastations on the onset of the rainy seasons has seriously decreased as so is the risk of flooding.

\subsection{Water Supply to the Community}

Water Supply to the Community through the surface impoundment has provided more reliable water availability all year round to the community. Even though the ground water supply through the use of hand pumps is relatively available, the problems of servicing the hand pumps rendered them inadequate when a break down occurs. The present water treatment system ensures a more wholesome (healthy) and dependable water to the community in the present and into the future. It will significantly reduce incidences of water borne diseases like dysentery with and dysentery without blood.

\subsection{Improvement in the River Biology}

The impoundment of the water in the reservoir has made water to be available all year round despite the level of sediment load. As a result there is a gradual generation of all year round aquatic ecosystem within the impoundment thereby encouraging the development of relevant benthic fauna and flora, both in quality and quantity in the reservoir and upstream, which could not have been possible without the reservoir due to the relative dryness of the river for parts of the year. Also perennial nature of the impoundment is encouraging the growth and development of a viable riparian ecosystem which will include micro- and macro- organisms including fishes and their supporting invertebrates. Ultimately fish development will increase to support regulated fishing as long as it does not compromise the integrity of the reservoir water as a drinking water source.

\subsection{Improvement of Agricultural Production}

The development of irrigation activities on the 70 hectares downstream of the reservoir is enabling the cultivation of more crops and additional area of land to increase rain fed agricultural production. The increased production has contributed to increased revenue to the average farming family, enhance their purchasing power, their standard of living and in the long run ensure food security for the nation. Also available has resulted in more water available for the livestock industry. This is further enhancing agricultural productivity and an improvement in national food security.

Improved water availability is also an encouragement to the domiciled Fulanis to engage in dry season growing of rich fodder crops for their livestock to prevent the stressful nomadic life which not only stress the cattle and lower their animal quality but also exposes the human beings to undue health risks. Such sedentarized livestock owners will be saved the drudgery and risks to life attendant to nomadic life and provide livestock owners with a more satisfying employment of tending to their cattle and have more opportunities for other productive ventures like fodder crops cultivation to feed their animals and for sale to other migrant herdsmen to earn more revenue. This enhances their standard of living.

\section{FAILURE OF DAMS IN NIGERIA}

Sherard et al, (1963) carried out an extensive survey on dam failures and he reported that failure in earth dams could be as a result of overtopping, embankment and foundation piping, differential settlement and cracks, embankment and foundation slides, slides during construction, earthquake damage, reservoir wave action, damage due to borrowing animals, damage caused by water soluble material, flow slides due to spontaneous liquefaction, and damage due to surface drying. In the early times Terzaghi in his experience in geotechnical engineering encountered many cases of failures - significantly due to lack of ability to predict and control ground water. Piping failures were abundant and also slope failures, bearing capacity failures and excessive settlements. (Burland, 2006) Anonymous, (2003) pointed out that, earth dam failures can be grouped into three general categories: overtopping failures, seepage failures, and structural failures. The three types of failure are often interrelated in a complex manner.

Three basic dam failures have occurred at Cham small earth dam;

a) Hydraulic failure - Overtopping and near overtopping.

b) Seepage failure - Piping at downstream toe of the dam.

c) Structural failure - Cracking at various points on crest, settlement near the right abutment and complete breach of the embankment (Plate-6). 


\section{Conclusion}

From the foregoing, the erection of the Small earth dam and its support projects of irrigation and domestic water treatment facilities have transformed the environment such that the constant fear of flooding and its attendant devastation every rainy season is no longer a reality. The project has provided all year round reliable availability of water for domestic and agricultural use such that there is improvement in the health and wellbeing of the populace of the community, while also providing additional source of revenue to members of the community, thus enhancing their standard of living. The environmental benefits of the dam to the community are numerous.

\section{Recommendation}

Earth dams in Nigeria fail as a result of human errors such as inadequate preliminary study on proposed construction site, discrepancies in the design, poor unqualified dam safety monitoring personnel on site and bad maintenance culture. The failure of Cham dam in particular can also be attributed to the hurried commissioning of the dam in 1992 without achieving the designed crest level among other reasons. The following recommendations are thus given with a view to reducing earth dam failures to the barest minimum in Nigeria:

a) Adequate study should be carried out on the project area to include, hydro-meteorology, geology and soil among others;

b) Design should be based on the results of the feasibility study carried out;

c) Projects should not be commissioned before they are fully completed;

d) Experts from all the relevant areas must be involved in the planning and development of the project;

e) Engineering procedure of project conception, implementation operation and maintenance should be strictly adhered to;

f) There should be a well designed and constructed spillway;

g) Construction should be strictly based on the design specifications and standards;

h) Side slopes in the upstream and downstream side of the dam should be about 3:1 as this provides a very reliable stability;

i) Allowance of $60 \mathrm{~cm}$ freeboard after settlement above maximum height of water if the length of the dam does not exceed $300 \mathrm{~m}$ and if larger than this, more than $60 \mathrm{~cm}$;

j) The downstream slope should be protected against rainfall erosion by heavy gravel or rock riprap. Sod may also be provided to guard against erosion if the rainfall is sufficient to grow and maintain grasses;

k) If highly permeable material would be used at all in constructing the dam, it will be found least objectionable if applied at the outer parts of the dam to aid drainage as a fill. Particularly attention must be given to the use of impervious materials in the core;

1) There should be no danger of over-topping by water;

$\mathrm{m})$ The seepage line should be well within the downstream face the dam. This is to prevent sloughing and possible failure;

n) Water passing through or under the dam should be unable to remove materials of the dam or the foundation;

o) There should be no opportunity for free flow of water from upstream to downstream face;

p) The foundation shear stress should be smaller than the shear strength to provide a suitable margin of safety;

q) Well equipped and adequate dam safety monitoring team should be on site all the time;

\section{REFERENCES}

- $\quad$ Ecosystem Consult Nig. Ltd. 2002. Environmental Impact Assessment of the Sorau small dam Project. A

- Technical report submitted to the Federal Ministry of Water Resources, Abuja, Nigeria, 56pp.

- Federal Environmental Protection Agency: (1992): Environmental Impact Assessment, Sectoral Guidelines.

- Agriculture and Rural Development Abuja, Nigeria.

- $\quad$ Keiser, J., De Castro, M. C., Maltese, M. F., Bos, R., Tanner, M., Singer, B. H. and Utzinger J. 2005.

- Effects of Irrigation and Large Dams on the Burden of Malaria on a Global and Regional Scale.

- American Journal of Tropical Hygiene. 72 (4):392 - 406

- Kondolf, G. M. 1997. Profile Hungry Water; Effects of dams and gravel mining on river channels.

- Environmental Management Vol.21 (4):533-551.

- Adeniji F. A. 2003. Re-advocating Conservation of Soil and Water Resources for Sustainable Development in North Eastern Nigeria. Proceedings of the 4th International Conference of the Nigerian Institution of Agricultural Engineers. 25: 7-16.

- Anonymous. 2003. Dam Safety: Earth Dam Failures, Fact Sheet 03-03. Indiana Department of Natural Resources, Water Division. http://www.in.gov/dnr/water.

- $\quad$ Arora K.R. 2001. Irrigation Water Power and Water Resources Engineering. Naisarak India: Standard 
Publishers.

- Burland J. 2006. Terzaghi: back to the future. Journal/Bulleting of Engineering Geology and Environment. http://www.springerlink.com. 66: 29-33.

- Gundiri M.N. 1984. Nigerian Register of Dams. Federal Ministry of Water Resources in conjunction with the National Sub-Committee on Dams (NSCD) and Nigeria Committee on Large Dams (NICOLD).

- Oskoorouchi A.M. 1988. Design of Detention Reservoirs and small Dams part-1. Lecture notes at the Post graduate Center in Irrigation Engineering Catholieke University Leuven, Belgium.

- $\quad$ Punmia B. C. and Lal P. B. B. 1992. Irrigation and Water Power Engineering. 12th Ed. J. udpur India. Laxmi Pupblications (P) Ltd.

- $\quad$ Qiang Z. 2003. Planning and design of rain water harvesting system. Proc. of the international training course on rainwater harvesting and utilization. Sept. 8-Oct. 22, Chinese and UNESCO.

- $\quad$ Sherard J.L., Richard S.D, Woodward J, Stanley N.S., Gizenski F., Willaim M.S. and B.S. Clevenger. 1963. Earth and Earth Rock Dams. John Willey and Sons Inc.

- $\quad$ Toro S.M. 1992. The activities of the Upper Benue River Basin Development Authority. Federal Ministry of Agriculture and Rural Development Abuja, Nigeria.

- Wikipedia Encyclopedia. 2008. "Water". http://en.wikipedia.org/wiki/Water. 